\title{
Editorial
}

\section{The Evolution of Critical Care Nephrology in Edmonton}

\author{
Sean M. Bagshaw R.T. Noel Gibney \\ Division of Critical Care Medicine, Faculty of Medicine and Dentistry, University of Alberta, Clinical Sciences \\ Building, Edmonton, Alberta, Canada
}

\begin{abstract}
The University of Alberta (UofA) in Edmonton, Canada has a rich and productive history supporting the development of critical care medicine, nephrology and the evolving subspecialty of critical care nephrology. The first hemodialysis program for patients with chronic renal failure in Canada was developed at the University of Alberta Hospital. The UofA is also recognized for its early pioneering work on the diagnosis, etiology and outcomes associated with acute kidney injury (AKI), the development of a diagnostic scheme renal allograft rejection (Banff classification), and contributions to the Renal Disaster Relief Task Force. Edmonton was one of the first centers in Canada to provide continuous renal replacement therapy. This has grown into a comprehensive clinical, educational and research center for critical care nephrology. Critical care medicine in Edmonton now leads and participates in numerous critical care nephrology initiatives dedicated to $\mathrm{AKI}$, renal replacement therapy, renal support in solid organ transplantation, and extracorporeal blood purification. Critical care medicine in Edmonton is recognized
\end{abstract}

across Canada and across the globe as a leading center of excellence in critical care nephrology, as an epicenter for research innovation and for training a new generation of clinicians with critical care nephrology expertise.

(c) 2016 S. Karger AG, Basel

\section{Introduction}

The University of Alberta (UofA) was founded in Edmonton in 1907 to provide higher education to the population of the newly created province of Alberta [1]. The Faculty of Medicine at the UofA was founded in 1920 , followed by the first medical students trained at the university graduating in 1925 . The first respiratory intensive care unit (ICU) in western Canada was developed at the University of Alberta Hospital (UAH) during the polio epidemic in 1957. Patients were supported using negative pressure ventilators, 'iron lungs' (fig. 1) $[3,4]$.

\section{KARGER}

E-Mail karger@karger.com

www.karger.com/bpu
(C) 2016 S. Karger AG, Basel

0253-5068/16/0414-000I\$39.50/0
Dr. R.T. Noel Gibney

2-124 Clinical Sciences Building 8440-112 ST NW

Edmonton, Alberta (Canada)

E-Mail ngibney@ualberta.ca 


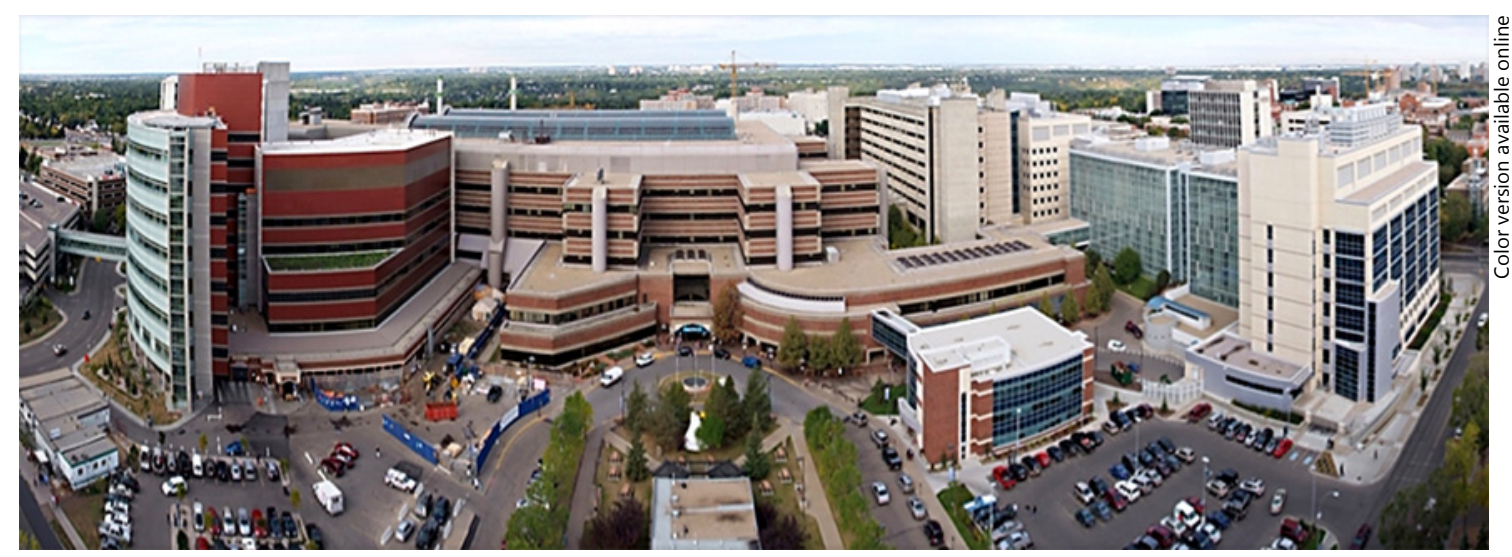

Fig. 1. The Walter C. Mackenzie Health Sciences Centre, Edmonton, Alberta which includes the UAH, Mazankowski Alberta Heart Institute, Stollery Children's Hospital, Alberta Transplant Institute and Alberta Diabetes Institute.

\section{Critical Care in Edmonton}

The first multisystem critical care units in Canada were developed in the late 1960s in Toronto, Edmonton and Winnipeg evolving from the post-polio respiratory ICUs. A fellowship program in Critical Care Medicine created in Edmonton by Dr. E. Garner King in 1970, was one of the first of its kind and trained physicians from Canada and beyond, many of whom went on to develop critical care programs elsewhere in this country and around the world. Initially, Critical Care Medicine resided within Dr. King's academic home, the Division of Pulmonary Medicine. However, over time, it became clear that Critical Care Medicine had practitioners who had varied backgrounds in Anesthesia, Surgery, Emergency Medicine and other medical specialties.

\section{Division of Critical Care Medicine}

In 1985, the Division of Critical Care Medicine was established under Dr. King as an Interdepartmental Division of the Faculty of Medicine. The Divisional Director reported jointly to the Dean and the Chairs of Medicine, Surgery and Anesthesia and attended the monthly meetings of the Dean with the Chairs. This Division was responsible for the development of residency and fellowship training programs in Critical Care Medicine. On a national level in Canada, the Royal College of Physicians and Surgeons of Canada officially recognized Critical Care Medicine as a specialty in 1986.

\section{Healthcare in Edmonton}

Edmonton, the capital of the western Canadian province of Alberta is the most northerly major city on Canada. It has a metropolitan population of 1.3 million as of 2014. The medical system in Edmonton provides tertiary care to Northern Alberta and quaternary care for a number of specialty areas including solid organ transplantation and complex pediatric surgery to the provinces of Alberta and Saskatchewan as well as the Northwest Territories and portions of Nunavut.

In 1995, the government of the province of Alberta disbanded the individual boards of the hospitals in the province and created regional health authorities. The Capital Health Authority created clinical departments including a clinical department of Critical Care Medicine which was for the first time primarily responsible for recruitment of intensivists. The clinical department was responsible for the delivery of critical care services in all 5 hospitals in the Edmonton region.

In 2002, the Director for the Clinical Department of Critical Care Medicine in the Edmonton region, Dr. Noel Gibney, was appointed as Divisional Director. This allowed the academic Division and the clinical Department to merge their vision, mission and goals. At this time, it was agreed within the Faculty of Medicine and Dentistry that it should be possible for faculty members to hold a primary appointment in the Division of Critical Care Medicine (DCCM) and secondary appointments, if desired, in other departments. This was important for intensivists to receive full credit for academic activities in critical care, which, prior to that time, were not always fully valued by the traditional base specialties. The ability
II

Blood Purif 2016;41:I-V

DOI: $10.1159 / 000441440$
Bagshaw/Gibney 
of academic intensivists to practice and function fully within the DCCM has been a major advance and has significantly facilitated the development of an active research program within the division.

\section{Nephrology in Edmonton}

The first hemodialysis program for patients with chronic renal failure in Canada was developed at UAH in Edmonton, where Dr. Ray Ulan performed the first hemodialysis treatment in the country, second in the world after Seattle, on a 17-year-old girl with chronic renal failure in December 1962 using a Scribner shunt [5]. Dr. Carl Kjellstrand, a nephrologist at UAH in the 1990s, was widely recognized for his early pioneering work on the diagnosis, etiology and outcomes associated with acute kidney injury (AKI) [6]. Dr. Kim Solez, a renal pathologist at the UAH provided one of the first descriptions of 'new ischemic tubular necrosis' in patients receiving intermittent hemodialysis (IHD) for AKI. He has provided leadership in the development of the Banff classification of the pathology of rejection in renal allografts [9].

\section{International Relief}

In 1978, following the Armenian earthquake, where many victims died of untreated crush injury-related acute renal failure, Dr. Solez and a number of colleagues founded the Renal Disaster Relief Task Force (RDRTF) [10]. Subsequently, the RDRTF has responded to most of the large earthquakes in developing countries. Dr. Valerie Luyckx, nephrologist at the UAH and Dr. Noel Gibney responded as members of the RDRTF following the catastrophic earthquake in Haiti in 2010 [11, 12]. They subsequently contributed to the development of the RDRTF recommendations for the management for crush injury in mass disasters [13].

\section{Critical Care Nephrology at the UofA, Edmonton}

The other teaching hospitals in Edmonton also played a significant role in the development of Edmonton's expertise in critical care nephrology. Continuous arteriovenous hemofiltration $(\mathrm{CAVH})$ and continuous arteriovenous dialysis (CAVHD) was first performed in the ICU at the Edmonton General Hospital by Dr. Noel Gibney, intensivist, in collaboration with Dr. Robert Lefebvre, nephrologist, in

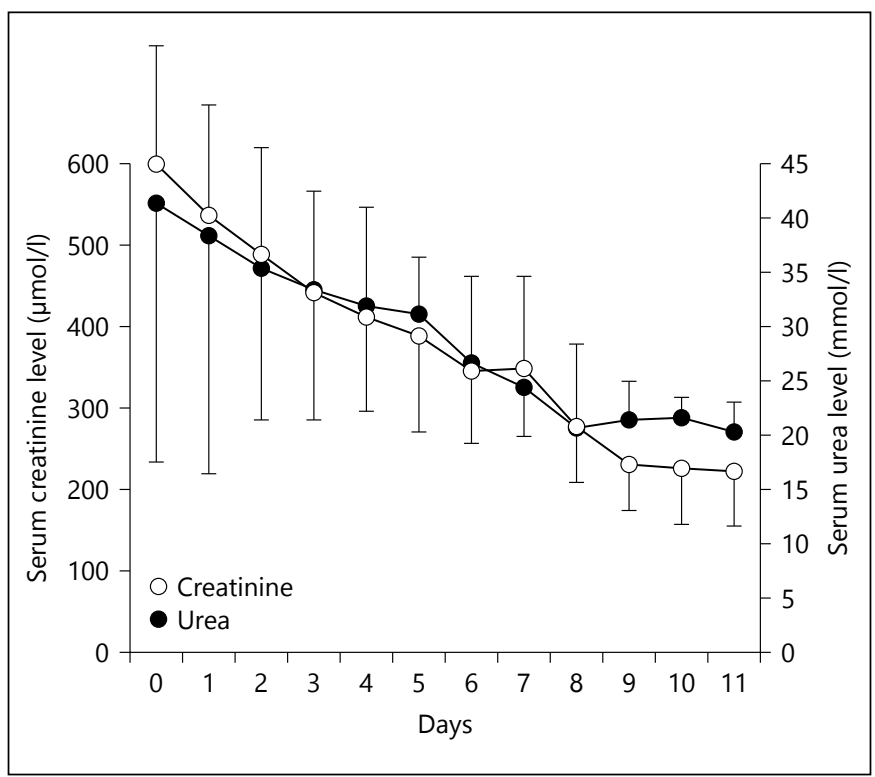

Fig. 2. Mean serum creatinine levels during 15 CAVHD treatments courses of 2 or more days in 12 patients. Vertical lines are SD. Adapted from [14].

1984 using an Amicon D20 hollow fiber hemofilter connected to femoral artery and femoral vein by single lumen cannulae. The circuit was anticoagulated with unfractionated heparin. Subsequently, CAVHD was performed using a hollow fiber hemofilter (Gambro Inc., Lund Sweden) with dialysate ports. Dianeal 0.5\% peritoneal dialysis solution with potassium chloride added as necessary was used as dialysate. Ultrafiltration was enhanced by increasing transmembrane pressure (TMP) by increasing blood pressure with vasoactive infusions as necessary to optimize the arteriovenous pressure gradient. On occasion, if this was not enough to achieve the desired rate of ultrafiltration, suction was applied using wall suction to the ultrafiltrate line to further increase TMP. Following this, CAVHD became the initial therapy of choice for most critically ill patients with AKI at EGH. Subsequently, because of perceived better flow characteristics and improved solute clearance, the Hospal parallel plate hemofilter was utilized as the main hemofilter [14]. The main challenges in performing CAVHD were the need for cannulation of the femoral artery and occasional injury to the artery requiring surgery for repair, and poor circuit blood flow in patients with low cardiac output. This modality was subsequently adopted in the ICUs at the other hospitals in the city (fig. 2).

Dr. Norman Kneteman performed the first liver transplant at the UAH in 1989. Many of the patients referred to this program had fulminant liver failure with associ- 
ated AKI and impaired kidney function. It was apparent that some of these patients were susceptible to developing acute intracranial hypertension during renal support with acute IHD. The work by Andrew Davenport in the United Kingdom (UK) showed that these acute increases in ICP could be mitigated by preferential use of continuous renal replacement therapy (CRRT) rather than IHD, which by that time had progressed to continuous venovenous hemofiltration supported by pump-driven blood flow [15]. Consequently, in 1997, 2 Gambro Prisma CRRT machines were purchased for the General Systems Intensive Care Unit at UAH. These proved successful in allowing the efficient delivery of RRT in unstable patients with all forms of AKI and, subsequently, additional machines were purchased for the other ICUs. Currently, there are 27 CRRT machines in the ICUs in the Edmonton region. Despite the availability of CRRT, these ICUs have also continued to provide IHD for hemodynamically stable patients and patients with dialyzable intoxications.

The DCCM pioneered the development of a protocol for regional citrate anticoagulation for CRRT and for using post hemofilter ionized calcium levels to monitor the anticoagulant effect in the hemofilter [16, 17]. This protocol was studied by Dr. Jim Kutsogiannis in a randomized controlled trial, which showed regional citrate to be more effective than unfractionated heparin $[18,19]$. This protocol was subsequently adopted in a number of other centers for clinical use [20,21]. More recently, we have been collaborating on a multicenter trial of the use of a dilute citrate solution for regional citrate anticoagulation for CRRT.

The availability of a range of renal replacement therapies and an interest in studying these therapies resulted in a number of residents studying nephrology to also become interested in critical care medicine and to train in this new specialty following certification by the Royal College of Physicians and Surgeons of Canada. The first of these was Dr. Neesh Pannu, facilitating clinical and academic interactions between Critical Care and Nephrology. Subsequently, Dr. Sean M. Bagshaw, an intensivist who had completed a fellowship in Critical Care Nephrology joined the group and initiated a research program. He successfully obtained a Career Award from the Alberta Heritage Foundation for Medical Research and has been recognized for his remarkable research output with a Canada Research Chair in Critical Care Nephrology. At present, the DCCM has 4 full time intensivist-nephrologists, trained in both critical care and nephrology, and 3 additional intensivists with interest and training in critical care nephrology. In addition, the DCCM has 50 intensivists who provide exemplary care to over 5,000 patients per year in 8 ICUs across 5 hospitals in the Edmonton area.

The DCCM has had an interest in kidney dysfunction associated with severe liver disease and has described the use of single pass albumin dialysis, initiated a molecular adsorbent recirculation system program and is evaluating the use of intraoperative CRRT during cadaveric orthotopic liver transplantation [22-24]. In addition, the DCCM has recruited an intensivist with training in gastroenterology and hepatology, Dr. Constantine (Dean) Karvellas, thereby opening further opportunities in the investigation and treatment of severe hepatic disease and kidney disease associated with liver failure.

Members of the DCCM have been actively involved in many of the Acute Dialysis Quality Initiative (ADQI) meetings, which have outlined the many challenges in the management of AKI and utilization of RRT and provided a roadmap for potentially valuable areas of study. In addition, the DCCM faculty has been actively involved in numerous international collaborative studies including the BEST Kidney Study, AKI-EPI and OPTIMAL-AKI trials [25-27]. There has also been active participation in interventional AKI trials (NaBic; OMAKI, STARRT-AKI and SPARK) as well as in industry-sponsored trials (EUPHRATES and SAPPHIRE) [28, 29]. The DCCM was actively involved in a study of critical care capacity in Canada, including CRRT resources during the $\mathrm{H} 1 \mathrm{~N} 1$ influenza pandemic [30,31]. Currently, there is work ongoing studying patient safety and quality improvement in AKI and during CRRT [32].

The DCCM has developed a fellowship program in Critical Care Nephrology and has now trained a number of individuals from Canada and around the world in this developing and exciting area of medicine.

\section{Conclusion}

The UofA has had a rich and productive history supporting the development of critical care medicine and the emerging subspecialty of critical care nephrology. The DCCM continues to be recognized as a leading center of excellence in critical care nephrology in Canada, as an epicenter for research innovation and for training a new generation of clinicians with critical care nephrology expertise.

\section{Acknowledgments}

Dr. Sean M. Bagshaw is supported by a Canada Research Chair in Critical Care Nephrology.
Blood Purif 2016;41:I-V DOI: $10.1159 / 000441440$
Bagshaw/Gibney 


\section{References}

1 http://www.ualbertacentennial.ca/.

2 Ross VJ: More than a Hospital: University of Alberta Hospitals, 1906-1986.

3 Slutsky AS: History of mechanical ventilation. From vesalius to ventilator-induced lung injury. Am J Respir Crit Care Med 2015;191: 1106-1115.

4 Grenvik A, et al: Evolution of the intensive care unit as a clinical center and critical care medicine as a discipline. Crit Care Clin 2009; 25:239-250.

5 http://www2.canada.com/edmontonjournal/ news/story.html?id=80381e51-1ece- $408 \mathrm{~b}$ a0a7-c421fa3a75ca.

6 Pru C, Kjellstrand CM: On the clinical usefulness of the FENa test in acute renal failure: a critical analysis. Proc Clin Dial Transplant Forum 1980;10:240-247.

7 Sang GL, Kovithavongs C, Ulan R, Kjellstrand CM: Sodium ramping in hemodialysis: a study of beneficial and adverse effects. Am J Kidney Dis 1997;29:669-677.

8 Racusen LC, Solez K: Nephrotoxic tubular and interstitial lesions: morphology and classification. Toxicol Pathol 1986;14:45-57.

9 Solez K, Axelsen RA, Benediktsson H, Burdick JF, Cohen AH, Colvin RB, Croker BP, Droz D, Dunnill MS, Halloran PF, et al: International standardization of criteria for the histologic diagnosis of renal allograft rejection: the Banff working classification of kidney transplant pathology. Kidney Int 1993;44:411-422.

10 Solez K, Bihari D, Collins AJ, et al: International dialysis aid in earthquakes and other disasters. Kidney Int 1993;44:479-483.

11 Vanholder R, Borniche D, Claus S, CorreaRotter R, Crestani R, Ferir MC, Gibney N, Hurtado A, Luyckx VA, Portilla D, Rodriguez S, Sever MS, Vanmassenhove J, Wainstein R: When the earth trembles in the Americas: the experience of Haiti and Chile 2010. Nephron Clin Pract 2011;117:c184-c197.

12 Vanholder R, Gibney N, Luyckx VA, Sever MS; Renal Disaster Relief Task Force: Renal disaster relief task force in Haiti earthquake. Lancet 2010;375:1162-1163.

13 Sever MS, Vanholder R; RDRTF of ISN Work Group on Recommendations for the Management of Crush Victims in Mass Disasters: Recommendation for the management of crush victims in mass disasters. Nephrol Dial Transplant 2012;27(suppl 1):i1-i67.

14 Gibney RT, Stollery DE, Lefebvre RE, Sharun CJ, Chan P: Continuous arteriovenous hemodialysis: an alternative therapy for acute renal failure associated with critical illness. CMAJ 1988;139:861-866.

15 Davenport A, Goldsmith HJ: Haemofiltration in management of patients with acute renal failure complicated by raised intracranial pressure. Lancet 1987;1:216.
16 Anderson BJ, Gibney RTN, Fox T, Westby J, Bradbury P, Stollery DE, Litwinowich B: Development of a protocol for continuous venovenous hemodiafiltration using regional anticoagulation with trisodium citrate in critically ill adults. Blood Purif 1998;16:116117.

17 Anderson BJ, Gibney RTN, Westby J, Bradbury P, Stollery DE, Litwinowich B: Regional anticoagulation using trisodium citrate for continuous venovenous hemodiafiltration in critically ill adults. Blood Purif 1998;16:103104.

18 Kutsogiannis DJ, Mayers I, Chin WD, Gibney RT: Regional citrate anticoagulation in continuous venovenous hemodiafiltration. Am J Kidney Dis 2000;35:802-811.

19 Kutsogiannis DJ, Gibney RT, Stollery D, Gao $\mathrm{J}$ : Regional citrate versus systemic heparin anticoagulation for continuous renal replacement in critically ill patients. Kidney Int 2005; 67:2361-2367.

20 Tobe SW, Aujla P, Walele AA, Oliver MJ, Naimark DM, Perkins NJ, Beardsall M: A novel regional citrate anticoagulation protocol for CRRT using only commercially available solutions. J Crit Care 2003;18:121-129.

21 Bagshaw SM, Laupland KB, Boiteau PJ, Godinez-Luna $\mathrm{T}$ : Is regional citrate superior to systemic heparin anticoagulation for continuous renal replacement therapy? A prospective observational study in an adult regional critical care system. J Crit Care 2005;20:155-161.

22 Karvellas CJ, Bagshaw SM, McDermid RC, Stollery DE, Bain VG, Gibney RT: A case-control study of single-pass albumin dialysis for acetaminophen-induced acute liver failure. Blood Purif 2009;28:151-158.

23 Karvellas CJ, Gibney N, Kutsogiannis D, Wendon J, Bain VG: Bench-to-bedside review: current evidence for extracorporeal albumin dialysis systems in liver failure. Crit Care 2007;11:215.

24 Townsend DR, Bagshaw SM, Jacka MJ, Bigam D, Cave D, Gibney RT: Intraoperative renal support during liver transplantation. Liver Transpl 2009;15:73-78.

25 Uchino S, Kellum JA, Bellomo R, Doig GS, Morimatsu H, Morgera S, Schetz M, Tan I, Bouman C, Macedo E, Gibney N, Tolwani A, Ronco C; Beginning and Ending Supportive Therapy for the Kidney (BEST Kidney) Investigators: Acute renal failure in critically ill patients: a multinational, multicenter study. JAMA 2005;294:813-818.
26 Hoste EA, Bagshaw SM, Bellomo R, Cely CM, Colman R, Cruz DN, Edipidis K, Forni LG, Gomersall CD, Govil D, Honoré PM, JoannesBoyau O, Joannidis M, Korhonen AM, Lavrentieva A, Mehta RL, Palevsky P, Roessler E, Ronco C, Uchino S, Vazquez JA, Vidal Andrade E, Webb S, Kellum JA: Epidemiology of acute kidney injury in critically ill patients: the multinational AKI-EPI study. Intensive Care Med 2015;41:1411-1423.

27 Bagshaw SM, Uchino S, Bellomo R, Morimatsu H, Morgera S, Schetz M, Tan I, Bouman C, Macedo E, Gibney N, Tolwani A, Oudemansvan Straaten HM, Ronco C, Kellum JA: Beginning and Ending Supportive Therapy for the Kidney (BEST Kidney) Investigators. Timing of renal replacement therapy and clinical outcomes in critically ill patients with severe acute kidney injury. J Crit Care 2009;24:129140 .

28 Hoste EA, McCullough PA, Kashani K, Chawla LS, Joannidis M, Shaw AD, Feldkamp T, Uettwiller-Geiger DL, McCarthy P, Shi J, Walker MG, Kellum JA; Sapphire Investigators: Derivation and validation of cutoffs for clinical use of cell cycle arrest biomarkers. Nephrol Dial Transplant 2014;29: 2054-2061.

29 Wald R, Adhikari NK, Smith OM, Weir MA, Pope K, Cohen A, Thorpe K, McIntyre L, Lamontagne F, Soth M, Herridge M, Lapinsky S, Clark E, Garg AX, Hiremath S, Klein D, Mazer CD, Richardson RM, Wilcox ME, Friedrich JO, Burns KE, Bagshaw SM: Comparison of standard and accelerated initiation of renal replacement therapy in acute kidney injury. Kidney Int 2015;88:897-904.

30 Fowler RA, Abdelmalik P, Wood G, Foster D Gibney N, Bandrauk N, Turgeon AF, Lamontagne F, Kumar A, Zarychanski R, Green R, Bagshaw SM, Stelfox HT, Foster R, Dodek P, Shaw S, Granton J, Lawless B, Hill A, Rose L, Adhikari NK, Scales DC, Cook DJ, Marshall JC, Martin C, Jouvet P; Canadian Critical Care Trials Group; Canadian ICU Capacity Group: Critical care capacity in Canada: results of a national cross-sectional study. Crit Care 2015;19:133.

31 Bagshaw SM, Sood MM, Long J, Fowler RA, Adhikari NK; Canadian Critical Care Trials Group H1N1 Collaborative: Acute kidney injury among critically ill patients with pandemic H1N1 influenza A in Canada: cohort study. BMC Nephrol 2013;14:123.

32 Rewa O, Villeneuve PM, Eurich DT, Stelfox HT, Gibney RT, Hartling L, Featherstone R, Bagshaw SM: Quality indicators in continuous renal replacement therapy (CRRT) care in critically ill patients: protocol for a systematic review. Syst Rev 2015;4:102.
The Evolution of Critical Care

Nephrology in Edmonton
Blood Purif 2016;41:I-V

DOI: $10.1159 / 000441440$ 